\title{
Evaluation of Five Hundred Patients using Ahmad's NPRT System for Documenting Male Pattern Baldness
}

\author{
Dr. Muhammad Ahmad* \\ Plastic \& Hair Restorative Surgeon, Aesthetic Plastic Surgery \& Hair Transplant Institute, H. 1-B, Main \\ Kohistan Road, F-8/3, Islamabad, Pakistan
}

*Corresponding Author: Dr. Muhammad Ahmad, Plastic \& Hair Restorative Surgeon, Aesthetic Plastic Surgery \& Hair Transplant Institute, H. 1-B, Main Kohistan Road, F-8/3, Islamabad, Pakistan, Email: plasticsurgeonpk@yahoo.com

\begin{abstract}
Background: Multiple classifications for male pattern baldness are mentioned in the literature. A new system is presented for documenting hair loss. The main aim of the study was to evaluate the practical application of the Ahmad's NPRT system.

Methods: The study was conducted in a private hair restoration clinic. The five hundred male patients of all ages were included presenting with varying degrees of hair loss. The age and family history were noted. The various points of the new system were noted, i.e., i. Norwood Scale (denoted by ' $N$ '), ii. Temporal Peaks/Points (denoted by letter ' $P$ ' and further subdivided into four grade from 0 to 3), iii. Reverse Thinning (denoted by letter ' $R$ 'and graded from 0 to 3), and iv. Overall Thinning (denoted by the letter ' $T$ ' and subdivided from 0 to 3 ).
\end{abstract}

Results: The mean age of the patients was 29.3 years, ranging from 17 years to 62 years. Type IV with its variants was the most common baldness pattern found in $29 \%$ of the men followed by type III (27.4\%). Varying grades of status of temporal peaks, reverse thinning and overall thinning were noted.

Conclusion: The new system was found to be helpful in ascertaining the exact situation of hair loss.

Keywords: Hair, Alopaecia, Classification

\section{INTRODUCTION}

Androgenic alopaecia is the commonest type of hair loss in men ${ }^{[1]}$. It is hereditary in nature and responds to androgens ${ }^{[2]}$. The pattern is predetermined by the genes and the hair follicles having specific receptors are affected ${ }^{[3]}$. In the androgenic alopaecia, a progressive hair loss is seen. The terminal hair turn into very fine, 'vellus hair' gradually ${ }^{[4]}$. Various classifications for documenting hair loss have been mentioned in the literature. The first attempt was done by Beek in 1950 on 1000 Caucasian males ${ }^{[5]}$. In 1951, Hamilton described his classification system in Caucasian and Chinese population ${ }^{[6]}$. In 1953, Ogata described evaluative varieties ${ }^{[7]}$. In 1969, Feit proposed a more detailed classification ${ }^{[8]}$. Setty simplified the Hamilton classification into three groups in $1970{ }^{[9]}$. In 1975, Rook and Dawber described five evolutive stages ${ }^{[10]}$. In the same year, Norwood also made a detailed classification than that of
Hamilton ${ }^{[11]}$. In 1976, Bouhanna proposed a simplified classification and 1981, Takashima mentioned his classification in Caucasian and Mongoloid population ${ }^{[12,13]}$. In 1984, Blanchard et al determined the measurements of six distances between fixed landmarks of face and the fluctuating borders of alopecia ${ }^{[14]}$. Savin proposed his classification in $1992^{[15]}$. In 1996, Bouhanna proposed the multi factorial classification [16]. Koo presented a new classification and subdivided into six subtypes in $200{ }^{[17]}$. In 2002, Cohen introduced his system and in the same year Lee et al proposed the basic and specific classification (BASP) of hair loss pattern ${ }^{[18,19]}$.

Although a large number of systems for classifying male pattern baldness are available today but these all have limitations. Some of these are too complicated while others do not describe the complete evolutionary stages of hair loss. All of the classification systems 
mainly describe the balding pattern and none of them touch certain key factors, i.e., the temporal peaks/points, the status of the donor area and the varying features of the baldness classified as 'non-specific' patterns. The Norwood classification is used as 'the gold standard' by majority of the hair restoration physicians but it has certain limitations too. It is also not helpful in determining the surgical plan.

The author has introduced a new system which maintains the Norwood scale as the main point and other points are added around it. The main aim of the study was to evaluate the practical application of the Ahmad's NPRT system.

\section{Materials AND MethodS}

The study was conducted in a private hair restoration clinic. The male patients of all ages were included in the study presenting with varying degrees of hair loss. The age and family history were noted. The various points of the new system were noted.

The Ahmad's NPRT system consists of four points.

a) Norwood Scale: It serves the main part of the classification and all subtypes and variants are included (Fig. 1).

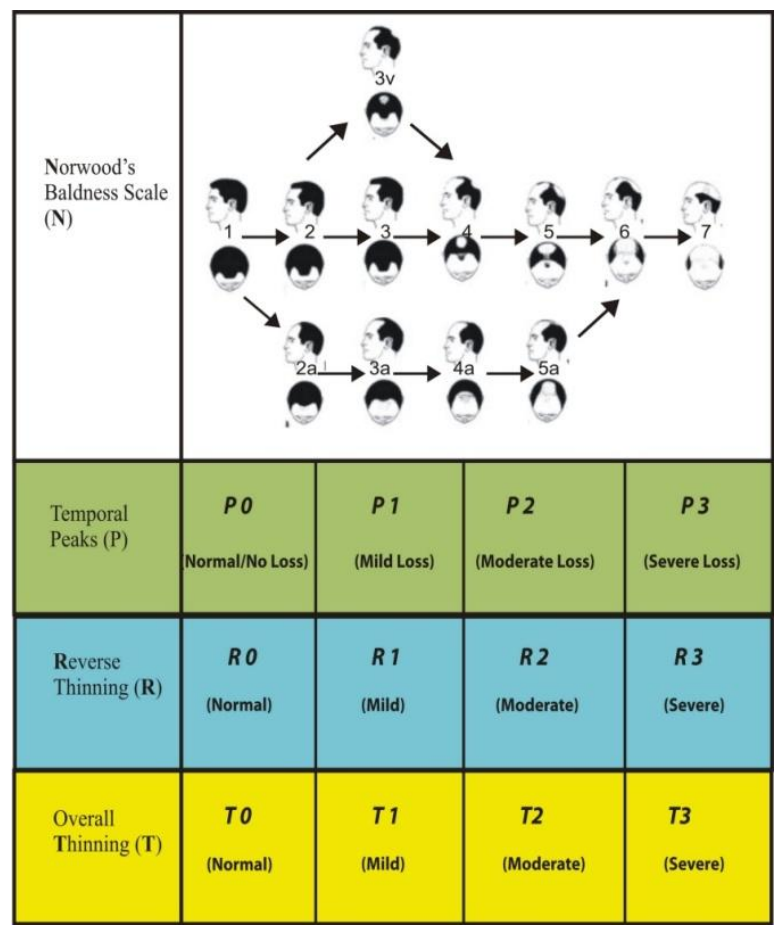

Figure1. Ahmad's NPRT System

b) Temporal Peaks/Points: It is denoted by letter ' $\boldsymbol{P}$ '. The different grades vary from 0 to 3 written with the letter 'P' (Fig. 2).

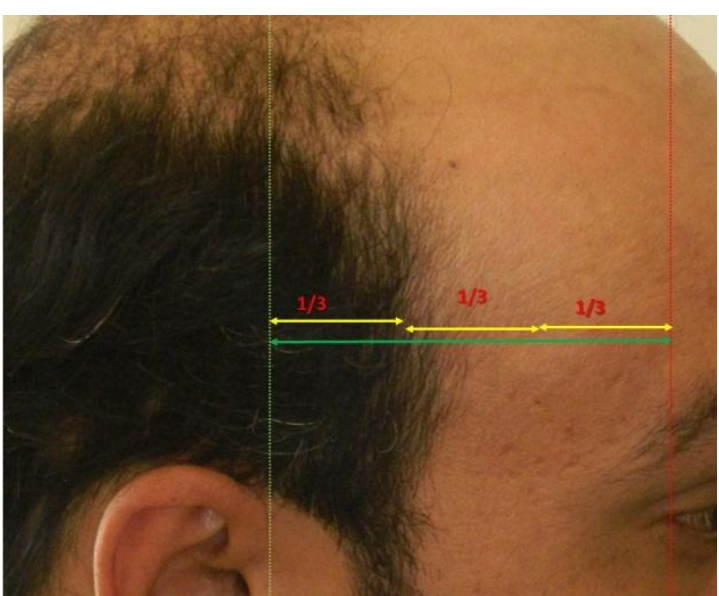

Figure2. Temporal points/peaks $(P)$

$\boldsymbol{P O}$ indicates 'No' hair loss at the temporal peaks/points.

$\boldsymbol{P 1}$ indicates the apex of the temporal peak (temporal point) is located not less than the junction of $1 / 3 \mathrm{rd}$ and $2 / 3 \mathrm{rd}$ of the distance between outer canthus to tragus.

$\boldsymbol{P 2}$ indicates the temporal point is located not less than the $1 / 2$ of the distance between outer canthus to tragus.

$\boldsymbol{P 3}$ indicates the reverse of $\boldsymbol{P 1}$,i.e., the temporal point is located at the distance less than $2 / 3 \mathrm{rd}$ and $1 / 3$ rd between outer canthus to tragus.

c) Reverse Thinning: It is denoted by letter ' $\boldsymbol{R}$ '. It is the hair loss in the occipital area and above the ears (mastoid area). 'Reverse thinning' means more skin is visible than hair. It also has 0 to 3 grades (Fig. 3).

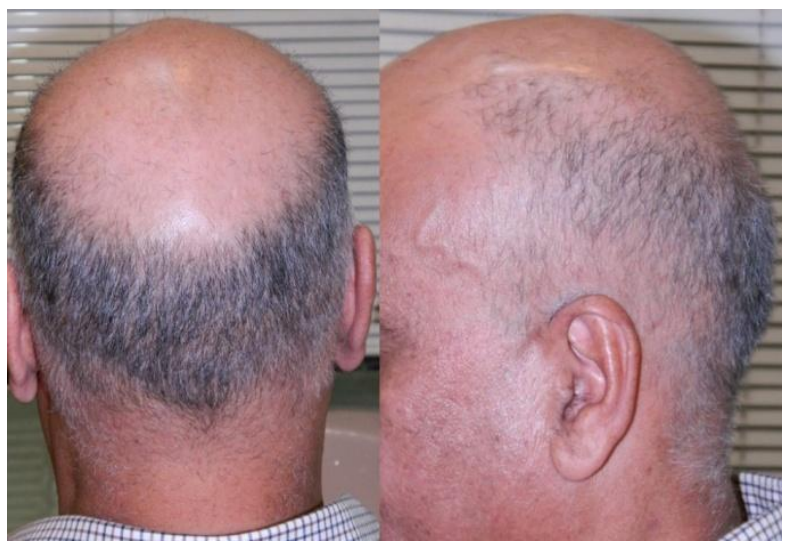

Figure3. Reverse Thinning $(R)$

$\boldsymbol{R} \boldsymbol{O}$ indicates 'No' reverse thinning.

$\boldsymbol{R} \boldsymbol{1}$ indicates 'mild reverse thinning', i.e., the loss of hair density is limited only to $1 \mathrm{~cm}$ above ears and/or occipital area (below the horizontal line joining both ear lobes)

$\boldsymbol{R} 2$ indicates 'moderate reverse thinning', i.e., the hair loss/decreased density is more than 1 
$\mathrm{cm}$ but less than $2 \mathrm{~cm}$ in occipital and/or mastoid area.

$\boldsymbol{R 3}$ indicates 'severe reverse thinning' and i.e., the decrease in density is more than $2 \mathrm{~cm}$ above the ears and/or occipital area.

d) Overall Thinning: It is denoted by the letter ' $\boldsymbol{T}$ ' (Fig. 4).

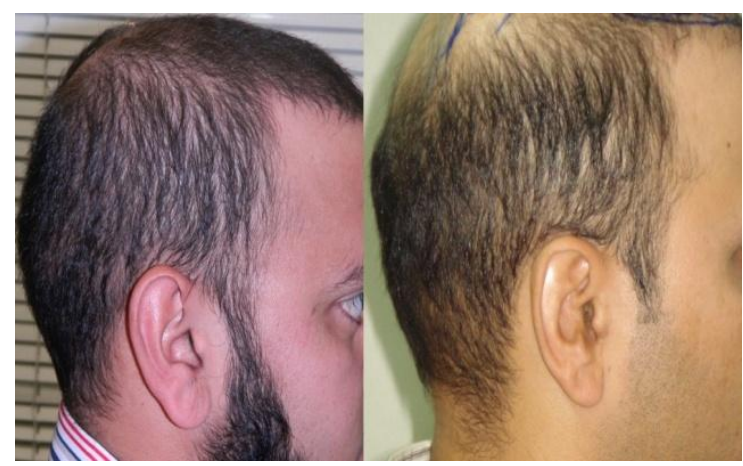

Figure4. Overall Thinning (T)

It varies from 0 to 3 grades. It describes the overall density of the donor area (behind the straight line from the tragus on sides and about 2 $\mathrm{cm}$ above the external occipital protuberance).
T0 indicates 'No' thinning

$\boldsymbol{T 1}$ indicates the 'mild' loss in density, i.e., more skin is visible than hair (less than 25\% loss).

$\mathbf{T} 2$ indicates the 'moderate' loss in density i.e., much skin is visible than hair (loss is more than $25 \%$ but less than $50 \%$ ).

T3 indicates 'severe' loss of density, i.e., too much skin is visible than hair (loss is more than $50 \%$ ).

The density can be measured at the level of external occipital protuberance (or $100 \mathrm{hair} / \mathrm{cm} 2$ can be taken as a reference value).

\section{RESULTS}

A total of 500 patients were included in the study. The mean age of the patients was 29.3 years, ranging from 17 years to 62 years. Type IV with its variants (IVa and IVv) was the most common baldness pattern found in $29 \%$ of the men followed by type III (with its variants IIIa and IIIv) observed in $27.4 \%$ of the patients. The mean age varied from 21.6 years to 39.9 years (Table 1).

Table1. Baldness pattern with age

\begin{tabular}{|c|c|c|c|c|}
\hline Norwood Scale & No. of patients & \% & Mean age (years) & Range (years) \\
\hline I & 9 & 1.8 & 21.6 & $17-24$ \\
\hline II & 21 & 4.2 & 24.2 & $19-36$ \\
\hline IIa & 26 & 5.2 & 24.6 & $19-32$ \\
\hline III & 62 & 12.4 & 26.8 & $19-40$ \\
\hline IIIa & 43 & 8.6 & 25.0 & $19-35$ \\
\hline IIIv & 32 & 6.4 & 24.1 & $19-36$ \\
\hline IV & 89 & 17.8 & 28.5 & $20-46$ \\
\hline IVa & 56 & 11.2 & 28.9 & $20-46$ \\
\hline V & 59 & 11.8 & 32.6 & $22-48$ \\
\hline Va & 31 & 6.2 & 33.1 & $22-44$ \\
\hline VI & 48 & 9.6 & 35.9 & $29-59$ \\
\hline VII & 24 & 4.8 & 39.9 & 62 \\
\hline
\end{tabular}

The types according to Norwood scale and the relevant status of temporal peaks $(\mathrm{P})$, reverse thinning $(\mathrm{R})$ and overall thinning $(\mathrm{T})$ were mentioned in Table 2.

Table2. Characteristics of the patients according to various point in Ahmad's NPRT system

\begin{tabular}{|c|c|c|c|c|c|c|c|c|c|c|c|c|c|}
\hline \multirow{2}{*}{$\begin{array}{l}\text { Norwood } \\
\text { Scale }\end{array}$} & \multirow{2}{*}{$\begin{array}{c}\text { No. of } \\
\text { Patients }\end{array}$} & \multicolumn{4}{|c|}{ Peaks (P) } & \multicolumn{4}{|c|}{ Reverse Thinning (R) } & \multicolumn{4}{|c|}{ Overall Thinning (T) } \\
\hline & & $P 0$ & $P 1$ & $P 2$ & P3 & RO & $R 1$ & $R 2$ & $R 3$ & TO & $T 1$ & $T 2$ & $T 3$ \\
\hline I & 9 & 6 & 3 & - & - & 7 & 2 & - & - & 7 & 1 & - & 1 \\
\hline II & 21 & 9 & 10 & 2 & - & 3 & 15 & 2 & 1 & 18 & 2 & 1 & - \\
\hline IIa & 26 & 12 & 11 & 3 & - & 4 & 15 & 5 & 2 & 22 & 2 & 1 & 1 \\
\hline III & 62 & 35 & 19 & 6 & 2 & 15 & 35 & 9 & 3 & 54 & 3 & 3 & 2 \\
\hline IIIa & 43 & 26 & 15 & - & 1 & 4 & 26 & 9 & 4 & 36 & 3 & 2 & 2 \\
\hline IIIv & 32 & 20 & 10 & 2 & - & 3 & 12 & 14 & 3 & 28 & 2 & 1 & 1 \\
\hline IV & 89 & 26 & 38 & 16 & 7 & 27 & 25 & 30 & 7 & 80 & 4 & 2 & 3 \\
\hline IVa & 56 & 17 & 15 & 14 & 10 & 6 & 29 & 18 & 3 & 51 & 2 & 1 & 2 \\
\hline $\mathbf{V}$ & 59 & 5 & 17 & 29 & 8 & 4 & 28 & 20 & 7 & 51 & 3 & 2 & 3 \\
\hline Va & 312 & 3 & 8 & 16 & 4 & 4 & 12 & 9 & 6 & 27 & 1 & 2 & 1 \\
\hline VI & 48 & 5 & 14 & 20 & 9 & 3 & 26 & 12 & 7 & 43 & 2 & 1 & 2 \\
\hline VII & 24 & 1 & 2 & 14 & 7 & 2 & 13 & 5 & 4 & 20 & 1 & - & 3 \\
\hline
\end{tabular}




\section{DISCUSSION}

Androgenic alopaecia is characterized by a progressive hair loss in which systemic androgens and genetic factors play a significant role ${ }^{[20]}$. It is evident from studies that hair loss patterns have regional differences ${ }^{[21,22]}$. The differences have also been noted among European and Asian population [11, 16]. A Chinese study showed different ratios in various cities of china ${ }^{[21]}$. Among various classification system of hair loss, the reliability of Norwood systems vs. basic and specific patterns (BASP) have been compared which concluded that BASP was better than Norwood's classification [23]. However there are certain limitations in BASP classification too, i.e., certain types of fronto-parietal and vertex regions (F2, F3) are confused with type $\mathrm{v}$. and type V of BASP is confused with Type V in Norwood system.

The main aims of the classification were the clinical application by practitioners and patients and to devise a surgical plan in the hair loss management. With the advent of latest technologies, better closure techniques in strip harvest, the advancements in follicular unit extraction technologies, the introduction of robots etc, all have almost obsoleted the use of flaps in hair restoration. Moreover none of the previous classifications address the key points, i.e., donor area and temporal points. The temporal peaks were previously classified by Brandy and Mayer but could not gain popularity $[24,25]$

The current system includes the status of donor area and the temporal peaks/points in a detailed manner. With the help of this new system, one can predict the current situation with the donor area status and also plan the surgical procedure. For example, in all the previous systems, one cannot predict the surgery in the last stage (e.g., Norwood scale VII) unless one knows the status of the donor area. A patient with Norwood type VII may or may not be a good candidate for surgery. With the help of this new system, we can predict the candidacy for surgery, e.g., a patient with Norwood type VII may be having R1T1 (a good candidate for surgery) or R3T3 (a bad candidate for surgery). The current system also predicts what could be the impact of future hair loss a patient with Norwood type III or IV with R1T1 at the age of 25 years may end in type VI with R3T3 after a decade. It also helps us to manage the medical treatment of hair loss. A patient with R3T3 may not be a good candidate for surgical hair restoration but can be a good candidate for medical management by drugs, lasers, platelets-rich plasma etc.

In the end, the inclusion of new points in Norwood scale increases the applicability of the classification system. It may help to avoid the misjudgments in the treatment plans.

\section{CONCLUSION}

The new system is helpful in ascertaining the exact situation of hair loss and can predict future hair loss as well.

\section{REFERENCES}

[1] The American Society of Plastic Surgeons. 2014 Quick Facts: Cosmetic and Reconstructive Plastic Surgery Trends. The American Society of Plastic Surgeons 2014, Arlington Heights, IL, USA, www.plastic surgery.org/ accessed on 01-01-2016.

[2] Hamilton JB. Male hormone stimulation is prerequisite and an incitant in commom baldness. Am J Anat 1942;71:451-80.

[3] Heilmann-Heimbach S, Hochfeld LM, Paus $\mathrm{R}$, Nöthen MM. Hunting the genes in male pattern alopecia: How important are they, how close are we, and what will they tell us? Exp Dermatol. 2016 Feb 4. doi: 10.1111/exd.12965. [Epub ahead of print]

[4] Unger WP. Shapiro R. eds. Hair transplantation. $4^{\text {th }}$ edition. Marcel Dekker Inc, New York; 2004.

[5] Beek CH. A study on extension and distribution of the human body hair. Dermatologica 1950;10:317.

[6] Hamilton JB. Patterned loss of hair in man: types and incidence. Ann NY Acad Sci 1951;53:708-28.

[7] Ogata T. Development of patterned alopecia. Sogo Rinsho 1953;2:101-6.

[8] Feit LJ. Pathoginic classification of male pattern baldness. Int Surg 1969;51:58-67.

[9] Setty LR. Hair patterns of the scalp of white and Negre male. Am J Phys Anthropol 1970;33:49-56.

[10] Rook A, Dawber R. Hair follicle structure, keratinization and the physical properties of hair. In: Rook A, Dawber R, eds. Diseases of the hair and scalp. Oxford: Blackwell Scientific, 1982:18-48.

[11] Norwood OT. Male pattern baldness; classification and incidnece. Southern Med J 1975;68(11):1359-65.

[12] Bouhanna P, Nataf J. A propos des transplantations de cuir chevelu: critiques et propositions. Rev Chir Esthet 1976; 7: 17-23. 
[13] Takashima I, Iju M, Sudo M. Alopecia androgenetica:its incidence in Japanese and associated conditions. In: Orfanos CE,ed. Hair research. Berlin: Springer-Verlag, 1981;287-93.

[14] Blanchard G, Blanchard B. Proposition d'une approche topographique de la transplantation capillaire et de la reduction tonsurale. Ann Chir Plast Esthet 1984;29:152-61.

[15] Savin RC. A method of visually describing and quantitating hair loss in male pattern baldness. $\mathrm{J}$ Invest Dermatol 1992; 98:604.

[16] Bouhanna P. Multifactorial classification of male and female androgenetic alopecia. Dermatol Surg. 2000; 26(6):555-61.

[17] Koo SH. Chung HS, Yoon ES, Park SH. A new classification of male pattern baldness and a clinical study of the anterior hairline. Aesthetic Plast Surg 2000;24:46-51.

[18] Cohen BH. The hair loss profile and index. J Cosmet Dermatol 2002;15: 19-23.

[19] Lee WS, Ro BI, Hong SP, Bak H, Sim WY, Kim do W, et al. A new classification of pattern hair loss that is universal for men and women: basic and specific (BASP) classification. J Am Acad Dermatol. 2007; 57(1):37-46.

[20] Sinclair R. Male pattern androgenic alopecia. Br Med J 1998; 317: 865-9.

[21] Wang TL, Zhou C, Shen YW, Wang XY, Ding $\mathrm{XL}$, Tian S, et al. Prevalence of androgenic alopecia in china: a community-based study in six cities. Br J Dermatol 2010; 162:843-7.

[22] Paik JH, Yoon JB, Sim WY, Kim BS, Kim NI. The prevalence and types of androgenic alopecia in Korean men and women. $\mathrm{Br} \mathrm{J}$ Dermatol 2001;145: 95-9.

[23] Hong H, Hong JI, Lee Y, Kang H, Choi GS, Lee WS. Reliability of the pattern hair loss classifications: a comparison of the basic and specific and Norwood-Hamilton classification. J Dermatol 2013; 40(2):102-6.

[24] Brandy DA. A method for evaluating and treating the temporal peak region in patients with male pattern baldness. Dermatol Surg 2002; 28(5): $394-400$.

[25] Mayer ML, Perez-Meza D. Temporal points: classification and surgical techniques. ESHRS Journal 2003; 3(2): $6-7$.

Citation: Dr. Muhammad Ahmad. Evaluation of Five Hundred Patients using Ahmad's NPRT System for Documenting Male Pattern Baldness. ARC Journal of Dermatology, 2017; 2(2):4-8. doi:dx.doi.org/10.2043 1/2456-0022.0202002

Copyright: (C) 2017 Authors. This is an open-access article distributed under the terms of the Creative Commons Attribution License, which permits unrestricted use, distribution, and reproduction in any medium, provided the original author and source are credited. 